\title{
Laparoscopic pancreaticoduodenectomy for pancreatic cancer: a hope or hype?
}

\author{
Weiwei Jin ${ }^{1}$, Tom Tan To Cheung ${ }^{2}$, Yiping Mou ${ }^{1}$ \\ ${ }^{1}$ Department of Gastroenterology and Pancreatic Surgery, Zhejiang Provincial People's Hospital, and Key Laboratory of Gastroenterology of \\ Zhejiang Province, Hangzhou 310014, China; ${ }^{2}$ Department of Surgery, Mary Hospital, University of Hong Kong, Hong Kong, China \\ Correspondence to: Yiping Mou, MD, FACS. Department of Gastroenterology and Pancreatic Surgery, Zhejiang Provincial People's Hospital, and Key \\ Laboratory of Gastroenterology of Zhejiang Province, Hangzhou 310014, China. Email: yipingmou@126.com. \\ Provenance and Peer Review: This article was commissioned by the editorial office, Hepatobiliary Surgery and Nutrition. The article has undergone \\ external peer review.
}

Submitted Mar 09, 2020. Accepted for publication May 06, 2020.

doi: $10.21037 / \mathrm{hbsn}-20-356$

View this article at: http://dx.doi.org/10.21037/hbsn-20-356

Pancreaticoduodenectomy (PD) is the optimal treatment for resectable pancreatic head tumors. With the development of laparoscopic skills, laparoscopic PD (LPD) has been considered safe and feasible with advantages of the minimally invasive approach (1). However, it is still controversial whether LPD is suitable for pancreatic cancer, including the learning curve, the perioperative outcomes and oncologic outcomes. Is LPD a hope or hype for pancreatic cancer?

The multicenter, patient-blinded, randomized trial by the Dutch Pancreatic Cancer Group was prematurely terminated because of the high 90 -day mortality (2). According to the paper, however, the high mortality was due to intraoperative vascular damage and postoperative morbidity, and all participating surgeons had performed 20 or more LPDs with $22 \%$ videos receiving a technical summary score of below average, showing the fact that the surgeons might have not overcome the learning curve.

A meta-analysis enrolling six studies with 282 LPDs and 982 open PDs showed that the two groups were similar in terms of number of lymph node, R0 resection, time of start of adjuvant chemotherapy after surgery, and 1- and 2-year survival rates, but the 3-, 4- and 5-year survival rates were higher in the LPD group (3). It means LPD is an alternative approach and sometimes is the better choice for pancreatic cancer. An international survey by Reames et al. (4) on 153 eligible pancreatic surgeons on four continents revealed that $33.3 \%$ of the surgeons would adopt the minimally invasive approach to PD for pancreatic cancer.
Among these surgeons, 52.9\% would use the laparoscopic approach, $23.5 \%$ would use robotic approaches, and $23.5 \%$ favored both laparoscopic and robotic approaches. In Miami International Evidence-based Guidelines (1), it showed that $92.5 \%$ experts and $1.0 \%$ agreed that minimally invasive pancreaticoduodenectomies were valid approaches for selected patients with adenocarcinoma.

More than 700 LPDs have been performed in our group since 2012, and our data showed that LPD was similar to open PD in terms of the number of harvested lymph nodes and the rate of R0 margin. In a propensity score matching study comparing LPD and open PD for pancreatic ductal adenocarcinoma at two highvolume centers, LPD and open PD achieved similar rates of complication and total survival (5). We have been following for 3 years a patient who received a combined surgery of LPD, right nephrectomy, tumor embolus removal, and plastic repair of the inferior vena cava (Figure 1). Now the patient is still alive, tumor-free and with good quality of life. The outcomes are encouraging. In surgical treatment of pancreatic cancer, LPD is an alternative way with advantages of the minimally invasive approach and potential oncologic benefits.

To make LPD for pancreatic cancer a hope not hype, the key points are as follows:

Firstly, for management of local advanced pancreatic cancer, it is essential to have robust and nuanced multidisciplinary discussion about neoadjuvant therapy modality, duration, sequencing, and how R0 resection can 

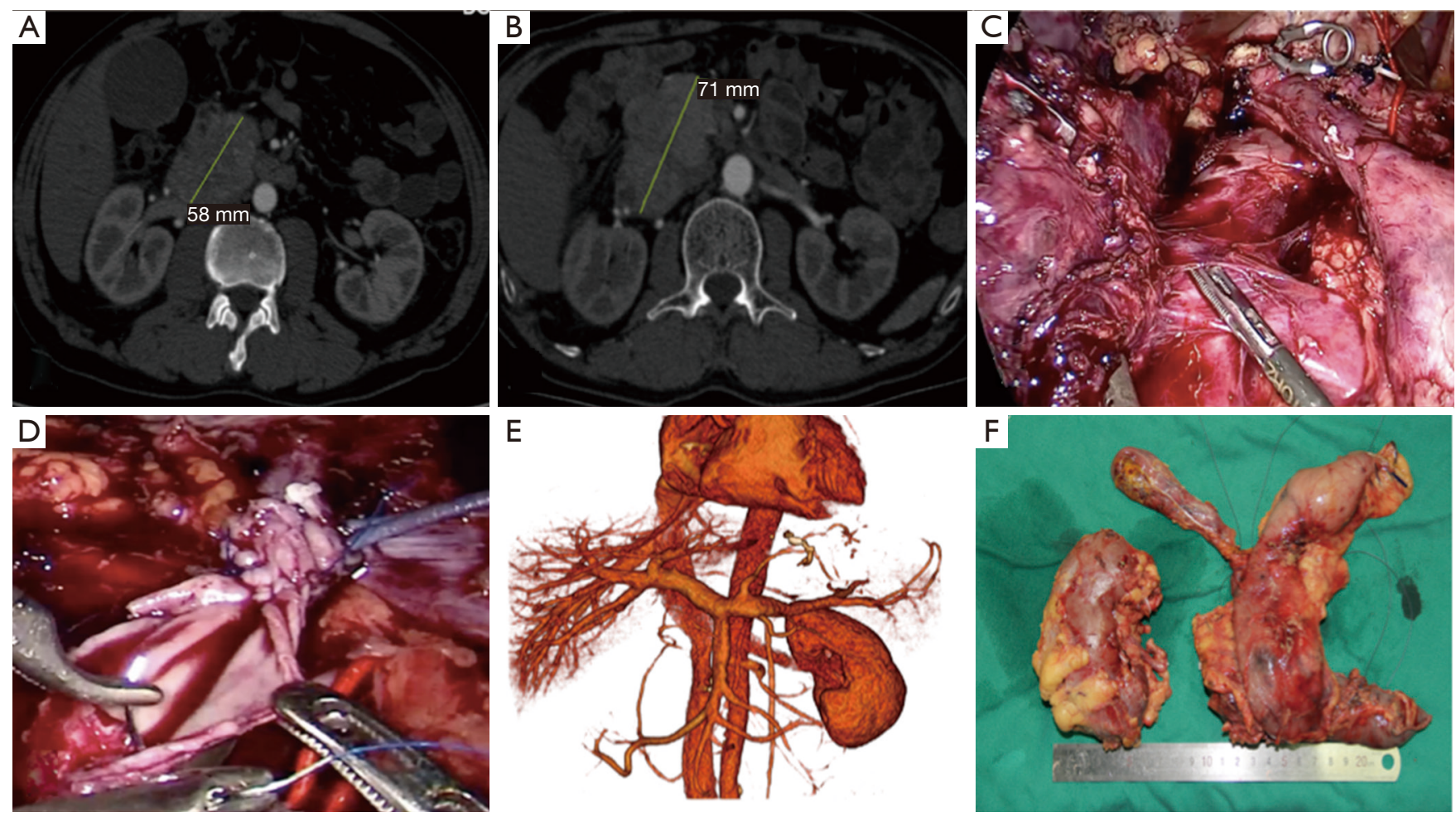

Figure 1 Clinical Images of the patient who received a combined surgery of LPD, right nephrectomy, tumor embolus removal and plastic of the inferior vena cava following neoadjuvant chemotherapy. (A) Enhanced CT scan before neoadjuvant chemotherapy; (B) enhanced CT scan after neoadjuvant chemotherapy; (C) the tumor invaded the right renal vein and the inferior vena cava; (D) plastic repair of the inferior vena cava; (E) three-dimensional model of veins after surgery; $(\mathrm{F})$ specimen.

be achieved. Many studies have shown that neoadjuvant therapy following surgery could benefit patients of pancreatic cancer (6). For examples, computed tomography and magnetic resonance imaging revealed tumor invasion of the inferior vena cava and the right renal vein (Figure 1A) but no metastasis was seen on positron emission tomography-computed tomography in our case. Endoscopic ultrasound-guided fine-needle biopsy indicated pancreatic neuroendocrine neoplasm (grade 3) on pathological examination. After 5 cycles of etoposide $(150 \mathrm{mg})$ and cisplatinum $(40 \mathrm{mg})$, the tumor increased slightly in size, but still there was no metastasis (Figure 1B). Thus, our multidisciplinary discussion concluded that extended PD might get $\mathrm{R} 0$ resection and benefits for this patient.

Secondly, appropriate strategies help surgeons perform LPD safely with R0 resection, especially for local advanced pancreatic cancer. We have summarized the "Easy First" approach for difficult LPD (7). It was designed to control intraoperative bleeding with tapes in case of close proximity of tumor to main vessels. The tapes can shut off the blood supply in bleeding. During the surgery for this case, Kocher maneuver could not be done as usual because the tumor had invaded the right renal vein and the inferior vena cava (Figure 1C). After exclusion of metastasis, the stomach, the bile duct and the jejunum were detached one by one. The pancreatic neck and the uncinate process were dissected and the inferior vena cava and the left renal vein were exposed. The inferior vena cava, with tapes shutting off its blood flow, was opened and all visible emboli were removed. The right renal vein was then detached, with guaranteed blood supply to the left renal vein. The margin was negative on frozen pathology. Finally, the inferior vena cava wall was plastic-repaired (Figure 1D).

Thirdly, in LPD, laparoscopic suturing is the base for successful resection and anastomosis. In this case, plastic repair of the inferior vena cava, pancreaticojejunostomy, choledochojejunostomy and gastrojejunostomy were all hand sewn under laparoscopy. The patient did not suffer pancreatic leakage or biliary leakage, and computed tomography at 1 year after surgery revealed patency of the 
inferior cava vein (Figure 1E). Simulation training and then on-site suturing during laparoscopic gastrointestinal surgery help improve laparoscopic suturing skills and overcome the learning curve.

In conclusion, for skilled surgeons, LPD is safe and feasible for patients of pancreatic cancer and can get good long-term oncologic outcomes. To make LPD for pancreatic cancer a hope not hype, nuanced multidisciplinary assessment, optimal neoadjuvant therapy, appropriate surgical strategies, and matured laparoscopic suturing are essential.

\section{Acknowledgments}

Funding: The study received funding from Key Research and Development Project of Zhejiang Province (2015C03049), Public Welfare Technology Plan of Zhejiang Province (LGC20H160003).

\section{Footnote}

Conflicts of Interest: All authors have completed the ICMJE uniform disclosure form (available at http://dx.doi. org/10.21037/hbsn-20-356). The authors have no conflicts of interest to declare.

Ethical Statement: The authors are accountable for all aspects of the work in ensuring that questions related to the accuracy or integrity of any part of the work are appropriately investigated and resolved.

Open Access Statement: This is an Open Access article distributed in accordance with the Creative Commons Attribution-NonCommercial-NoDerivs 4.0 International License (CC BY-NC-ND 4.0), which permits the non- commercial replication and distribution of the article with the strict proviso that no changes or edits are made and the original work is properly cited (including links to both the formal publication through the relevant DOI and the license). See: https://creativecommons.org/licenses/by-nc-nd/4.0/.

\section{References}

1. Asbun HJ, Moekotte AL, Vissers FL, et al. The Miami International Evidence-Based Guidelines on minimally invasive pancreas resection. Ann Surg 2020;271:1-14.

2. van Hilst J, de Rooij T, Bosscha K, et al. Laparoscopic versus open pancreatoduodenectomy for pancreatic or periampullary tumours (LEOPARD-2): a multicentre, patient-blinded, randomised controlled phase $2 / 3$ trial. Lancet Gastroenterol Hepatol 2019;4:199-207.

3. Chen K, Zhou Y, Jin W, et al. Laparoscopic pancreaticoduodenectomy versus open pancreaticoduodenectomy for pancreatic ductal adenocarcinoma: oncologic outcomes and long-term survival. Surg Endosc 2020;34:1948-58.

4. Reames BN, Blair AB, Krell RW, et al. Management of locally advanced pancreatic cancer: results of an international survey of current practice. Ann Surg 2019. [Epub ahead of print].

5. Zhou W, Jin W, Wang D, et al. Laparoscopic versus open pancreaticoduodenectomy for pancreatic ductal adenocarcinoma: a propensity score matching analysis. Cancer Commun (Lond) 2019;39:66.

6. Gemenetzis G, Groot VP, Blair AB, et al. Survival in locally advanced pancreatic cancer after neoadjuvant therapy and surgical resection. Ann Surg 2019;270:340-7.

7. Jin WW, Ajoodhea H, Mou YP, et al. Tips of laparoscopic pancreaticoduodenectomy for borderline resectable pancreatic cancer: "easy first" approach. Transl Cancer Res 2016;5:613-7.
Cite this article as: Jin W, Cheung TTT, Mou Y. Laparoscopic pancreaticoduodenectomy for pancreatic cancer: a hope or hype? HepatoBiliary Surg Nutr 2020;9(3):388-390. doi: 10.21037/ hbsn-20-356 